\title{
Screening and Stepped Care Targeting Psychological Distress in Patients With Metastatic Colorectal Cancer: The TES Cluster Randomized Trial
}

Claudia S.E.W. Schuurhuizen, MDa,b; Annemarie M.J. Braamse, PhDc; Aartjan T.F. Beekman, PhD; Pim Cuijpers, PhDd; Mecheline H.M. van der Linden, PhDe; Adriaan W. Hoogendoorn, $\mathrm{PhD}^{\mathrm{b}}$; Hans Berkhof, PhD;

Dirkje W. Sommeijer, MD, PhDg; Vera Lustig, MDg; Suzan Vrijaldenhoven, MD, PhDh; Haiko J. Bloemendal, MD, PhDi; Cees J. van Groeningen, MD, PhDi; Annette A. van Zweeden, MD;; Maurice J.D.L. van der Vorst, MDk; Ron Rietbroek, MD';

Cathrien S. Tromp-van Driel, MDm; Machteld N.W. Wymenga, MD, PhD ${ }^{\text {; }}$ Peter W. van der Linden, MD, $\mathrm{PhD}^{\circ}$;

Aart Beeker, MD'; Marco B. Polee, MD, PhDq; Erdogan Batman, MDr; Maartje Los, MD, PhDs; Aart van Bochove, MD'; Jan A.C. Brakenhoff, MD"; Inge R.H.M. Konings, MD, PhDa; Henk M.W. Verheul, MD, PhD ${ }^{a, *}$; and Joost Dekker, PhD ${ }^{b, *}$

\section{ABSTRACT}

Background: This study evaluated the effectiveness of a screening and stepped care program (the TES program) in reducing psychological distress compared with care as usual (CAU) in patients with metastatic colorectal cancer starting with first-line systemic palliative treatment. Patients and Methods: In this cluster randomized trial, 16 hospitals were assigned to the TES program or CAU. Patients in the TES arm were screened for psychological distress with the Hospital Anxiety and Depression Scale and the Distress Thermometer/Problem List (at baseline and 10 and 18 weeks). Stepped care was offered to patients with distress or expressed needs, and it consisted of watchful waiting, guided self-help, face-to-face problem-solving therapy, or referral to specialized mental healthcare. The primary outcome was change in psychological distress over time, and secondary outcomes were quality of life, satisfaction with care, and recognition and referral of distressed patients by clinicians. Linear mixed models and effect sizes were used to evaluate differences. Results: A total of 349 patients were randomized; 184 received the TES program and 165 received CAU. In the TES arm, $60.3 \%$ of the patients screened positive for psychological distress, $26.1 \%$ of which entered the stepped care program $(14.7 \%$ used only watchful waiting and $11.4 \%$ used at least one of the other treatment steps). The observed low use of the TES program led us to pursue a futility analysis, which showed a small conditional power and therefore resulted in halted recruitment for this study. No difference was seen in change in psychological distress over time between the 2 groups (effect size, $-0.16 ; 95 \% \mathrm{Cl},-0.35$ to $0.03 ; P>05$ ). The TES group reported higher satisfaction with the received treatment and better cognitive quality of life (all $P<.05$ ). Conclusions: As a result of the low use of stepped care, a combined screening and treatment program targeting psychological distress in patients with metastatic colorectal cancer did not improve psychological distress. Our results suggest that enhanced evaluation of psychosocial concerns may improve aspects of patient well-being.

J Natl Compr Canc Netw 2019;17(8):911-920 doi: $10.6004 /$ jnccn.2019.7285

\section{Background}

Cancer diagnosis and treatment are often associated with elevated levels of psychological distress, ${ }^{1,2}$ which may cause poorer quality of life (QoL), reduced adherence to treatment, and potentially a poorer prognosis. ${ }^{3-5}$ Routine screening for distress is recommended by a number of major cancer organizations, with the assumption that identification of elevated levels of distress will result in increased uptake of psychosocial services and reduction in distress. ${ }^{2,6}$ Psychosocial interventions and social support for patients with diagnosed distress have been shown to be

a Department of Medical Oncology, VU University Medical Center, Cancer Center Amsterdam, Amsterdam; ${ }^{b}$ Department of Psychiatry and Amsterdam Public Health Research Institute, VU University Medical Center, Amsterdam; 'Department of Medical Psychology, Cancer Center Amsterdam, Amsterdam Public Health Institute, Academic Medical Center, Amsterdam; 'Department of Clinical Psychology, VU University, Amsterdam; 'Department of Medical Psychology, and 'Department of Clinical Epidemiology and Biostatistics, VU University Medical Center, Amsterdam; 9Department of Medical Oncology, Flevoziekenhuis, Almere; ' ${ }^{\text {h}}$ Department of Medical Oncology, Noordwest Ziekenhuisgroep, Alkmaar; 'Department of Medica Oncology, Meander Medical Center, Amersfoort; 'Department of

Medical Oncology, Hospital Amstelland, Amstelveen; ${ }^{k}$ Department of Medical Oncology, Rijnstate Hospital, Arnhem; 'Department of Medical Oncology, Red Cross Hospital, Beverwijk; ${ }^{m}$ Department of Medical Oncology, Noordwest Ziekenhuisgroep, Den Helder; ${ }^{n}$ Department of Medical Oncology, Medisch Spectrum Twente, Enschede; ${ }^{\circ}$ Department of Medical Oncology, Spaarne Gasthuis, Haarlem; PDepartment of Medical Oncology, Spaarne Gasthuis, Hoofddorp; ${ }^{9}$ Department of Medical Oncology, Medical Center Leeuwarden, Leeuwarden; 'Department of Medical Oncology, Alrijne Hospital, Leiden; 'Department of Medical Oncology, St. Antonius Hospital, Nieuwegein; 'Department of Medical Oncology, Zaans Medical Center, Zaandam; and "Department of Medical Oncology, Waterland Hospital, Purmerend, the Netherlands.

*These authors contributed equally. 
effective, ${ }^{7-11}$ but so far no conclusive evidence shows that the combination of screening and subsequent treatment of distress actually improves patient outcomes (supplemental eAppendix 1 and eTable 1, available with this article at JNCCN.org). It has been suggested that for screening programs to be effective, they should be designed to target and follow up on patients' actual needs in order to direct patients to appropriate psychosocial services. ${ }^{12,13}$ In line with these suggestions, we developed the TES program, which combines targeted selection (T), enhanced care (E), and referral to well-described effective interventions using a stepped care-oriented approach (S) to create optimal conditions for a screening and treatment program targeting psychological distress. The goal of this cluster randomized trial (CRT) was to assess the effectiveness of the TES program in improving psychological distress compared with care as usual (CAU) in patients with metastatic colorectal cancer (mCRC) starting with first-line systemic palliative treatment. Secondary goals were to assess effects of the TES program on QoL, patient satisfaction with care offered, actual recognition and management of distressed patients by clinicians, and evaluation of the costeffectiveness of the TES program compared with CAU.

\section{Patients and Methods}

\section{Study Design and Population}

This study was a multicenter CRT approved by the medical ethics committee of VU University Medical Center and registered in the Netherlands Trial Register (NTR4034). An extensive description of the study protocol was published previously. ${ }^{14}$ All procedures were in accordance with the ethical standards of the medical ethics committees and with the Helsinki declaration.

Patients were recruited from the medical oncology departments of 16 participating hospitals in the Netherlands between July 2013 and October 2016. Eligible patients had a diagnosis of $\mathrm{mCRC}$, were scheduled to start palliative treatment with first-line chemotherapy, and had a life expectancy of $>3$ months. Exclusion criteria were age $<18$ or $>85$ years, insufficient command of the Dutch language, recent psychotherapy (in the past 3 months, at least one session every 2 weeks), and severe psychopathology (ie, mental illnesses that required [acute] inpatient treatment). All patients provided informed consent.

\section{Randomization and Blinding}

In this CRT, hospitals were selected as the unit of randomization to avoid contamination of treatment between groups. The randomization procedure was performed by a blinded statistician before patient recruitment. Blinding of patients, oncologists, nurses, and psychologists was not possible, owing to the nature of the intervention. Statistical analyses were performed blindly.
TES Program and CAU

Patients in the hospitals assigned to the TES arm were screened for psychological distress by a trained nurse/ clinical nurse specialist before the start of treatment ( 0 weeks) and 10 and 18 weeks thereafter. Screening was performed using the Hospital Anxiety and Depression Scale (HADS) ${ }^{15}$ and Distress Thermometer/Problem List (DT/PL). ${ }^{16,17}$ Scores of $\geq 13$ on the HADS ${ }^{15}$ or $\geq 5$ on the $\mathrm{DT}^{16}$ were seen as indicators of elevated psychological distress. After reviewing the distress scores with the patient, the trained nurses offered treatment in the form of stepped care to patients scoring above the cutoff scores of either screening tool and to those expressing the need for receiving psychosocial care. The steps included (1) watchful waiting, (2) a guided self-help program via the Internet or a booklet, (3) face-to-face problem-solving treatment offered by a trained nurse, and (4) referral to specialized psychosocial services or prescription of psychotropic medication. ${ }^{14,18} \mathrm{~A}$ diagnostic evaluation and needs assessment were performed by a psychologist after patients completed step 2 or at step 4 for patients who were immediately referred to specialized psychosocial services without participating in the previous steps. In contrast, in the hospitals assigned to $\mathrm{CAU}$, distress was identified by oncologists and nurses on an ad hoc basis only. For these patients, nonstandardized regular care was delivered in the form of advice or referral to other services. Three hospitals assigned to CAU introduced screening for psychological distress. Contrary to the TES program, screening in these hospitals was used as a standalone tool, without standardized follow-up and algorithms to guide triage. Patients from these 3 hospitals were excluded in a sensitivity analysis (see later discussion).

\section{Outcomes}

In both treatment arms, outcome measures were collected at baseline (T0), shortly after start of treatment (T1), and after 10 (T2), 24 (T3), and 48 (T4) weeks. The primary outcome was the difference in course of distress measured with the HADS ${ }^{19}$ between treatment arms over time. The HADS is a 14-item self-assessment scale for measuring distress, with a total score that ranges from 0 to $42 .{ }^{15,20}$ Secondary outcomes were differences in the course over time in QoL, assessed with the functioning scales and global score of the EORTC QoL of Cancer Patients questionnaire (EORTC QLQ-C30, version 3.0), ${ }^{21}$ patients' evaluation of psychosocial care assessed with the Client Satisfaction Questionnaire-8, ${ }^{22}$ and actual recognition and referral related to psychological distress by clinicians in both treatment arms assessed by data extracted from medical records. Results on cost-effectiveness will be reported elsewhere.

\section{Sample Size}

The sample size calculation was based on the effectiveness of screening and treatment in all patients in the TES group, 
including those who were not offered or did not use stepped care after screening. The expected proportion of patients in the TES group treated for psychological distress was $33 \%,{ }^{1}$ in whom an effect size (ES) of $d=0.54$ was expected. $^{23}$ The remaining $67 \%$ of patients without treatment had an expected ES of $d=0$. The overall expected ES was therefore $d=0.18$. To show this effect on the primary outcome measure (ie, HADS) using a longitudinal design with 4 follow-up measurements, setting the within-subject correlation at $\rho=0.3, \alpha=0.05$ (2-tailed), and power $(1-\beta)=$ 0.80 , a total of 302 patients was needed in each group. Assuming an intracluster correlation of $0.005,{ }^{24}$ a total of 715 patients was needed (ie, 359 in each group).

\section{Statistical Analyses}

Analyses were based on the intention-to-treat principle. Descriptive statistics were used to describe the baseline values of demographic and clinical variables in both arms. Linear mixed model (LMM) analyses were conducted to evaluate the differences in psychological distress and secondary outcomes between the TES and CAU arms. Both discrete time and linear time models were conducted. The LMMs considered 3 levels: measurements of individuals at the lowest level, individuals at the second level, and hospitals at the highest level. In the discrete time models, fixed effects were estimated for the 4 time indicators, for the 4 group-by-time 2-way interaction terms, and for disease progression that we added as a covariate. In the linear time model, fixed effects were estimated for time, the group-by-time 2-way interaction term, and for progression as a covariate. It should be noted that no main effect for group membership was estimated, thus correcting for baseline differences between the 2 intervention groups. ${ }^{25}$ At the second level, error terms within persons were allowed to be correlated according to an unstructured covariance matrix, whereas at the highest level, a random intercept for hospitals was used. Cohen's formula was used to calculate ESs from the estimated differences, using pooled pretest SDs. ${ }^{26} \mathrm{LMM}$ analyses handle missing observations caused by dropout under the missing-atrandom assumption. A sensitivity analysis was performed excluding patients enrolled in the 3 hospitals assigned to CAU that offered routine screening for psychological distress. For all statistical analyses, $P<.05$ was considered statistically significant. Data were analyzed using SPSS Statistics, version 22 (SPSS Inc.) and STATA, version 15 (StataCorp LLP).

\section{Results}

In-Between Futility Analysis

After recruitment of 321 patients, the observed proportion of patients receiving active treatment (not including watchful waiting) in the TES group was $8.7 \%$ (95\% CI, $5.1 \%-13.7 \%$ ), instead of the initially expected proportion of $33 \%$. The low uptake of active treatment resulted in a decrease of the expected ES. An unplanned futility analysis showed that with the planned number of 715 patients, the conditional power would be small (power, 0.11; supplemental eTable 2). The planned power of 0.80 would require recruitment of an unrealistic number of patients $(n=33,318)$. To prevent burdening additional patients in palliative treatment, the Medical Ethics Committee recommended closing the study for further patient entry and reporting results on those already included.

\section{Study Population}

Medical oncology departments in 16 participating hospitals in the Netherlands consented to participate and were allocated to either the TES program $(n=8)$ or CAU $(n=8)$. No hospital dropped out during the study. The first patient was enrolled on July 29, 2013, and the final assessment of the last patient was performed on October 20, 2017. Of 393 patients meeting the inclusion criteria and willing to participate, 349 participated in the study: 184 in the TES arm and 165 in the control arm receiving CAU (Figure 1). After 48 weeks of follow-up (T4), 110 patients $(59.8 \%)$ in the TES arm and 87 patients $(52.7 \%)$ in the CAU arm completed the outcome assessment. During the study, 98 patients died (47 [25.5\%] in the TES group and 51 [30.9\%] in the CAU group; $P=.263$ ).

At baseline, the TES and CAU groups were comparable regarding sociodemographic and most clinical characteristics (Table 1 and supplemental eTable 3). Patients in the TES arm received prior treatments for their metastases more often than those receiving CAU $(27.7 \%$ vs $15.2 \%$, respectively), and presented with peritoneal lesions more frequently (31.0\% vs $20.0 \%$, respectively) (supplemental eTable 3). Mean HADS scores at baseline were lower in patients assigned to the TES arm than in those assigned to the CAU arm (supplemental eTables 3 and 4). The EORTC QLQ-C30 at baseline showed better scores for role functioning and social functioning in the TES group. When baseline characteristics were compared between patients who completed the study and those who dropped out before the last assessment, we observed that completers had better ECOG performance status scores and were more often men (all $P<.05$; data not shown).

\section{TES Intervention}

According to protocol, 552 screenings had to be performed and subsequently evaluated by clinical nurse specialists in the 184 patients enrolled in the TES arm (ie, 3 screenings per patient). A total of 480 screenings and 


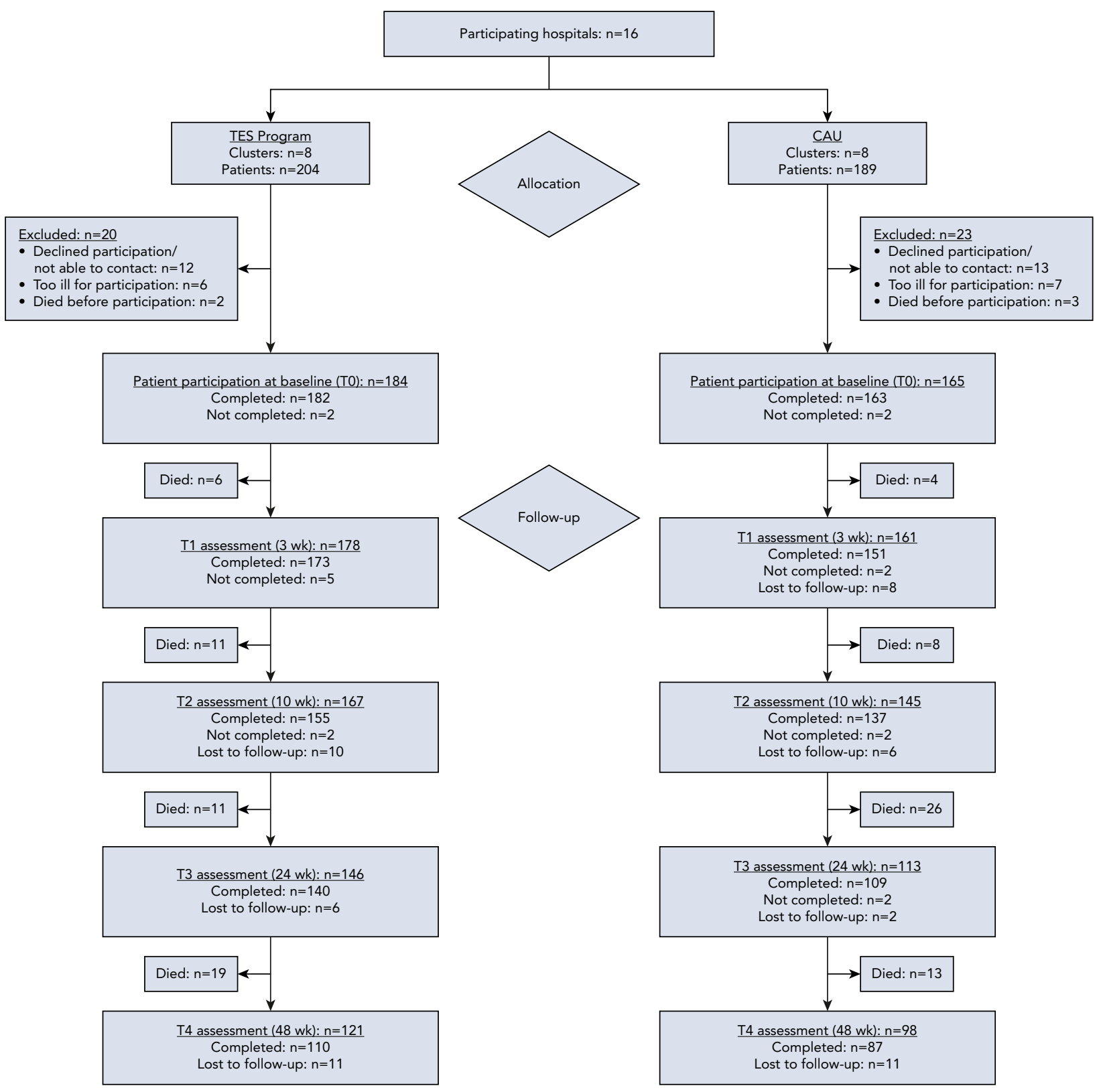

Figure 1. CONSORT diagram: study flowchart. Patients who did not complete an assessment were kept in the analysis and handled as missing observations.

Abbreviations: CAU, care as usual; TES, targeted selection (T), enhanced care $(E)$, and referral to well-described effective interventions using a stepped care-oriented approach (S).

evaluations (87.0\%) were accomplished in the hospitals assigned to TES. Of the 72 screenings not accomplished, 35 were the result of patient drop-out due to disease progression or death and the remaining 37 were missed (6.7\%) (Figure 2).

Of 184 patients in the TES arm, 111 (60.3\%) screened positive for elevated distress as assessed by the HADS or the DT/PL on at least one of the screenings (Figure 2). A total of 46 patients $(25.0 \%)$ entered stepped care after screening, and 2 without elevated distress scores entered after expressing the need for psychosocial care; 27 (14.7\%) used only watchful waiting and 21 (11.4\%) used at least one of the other steps (Table 2). Overall, a total of 62 interventions were used by these 48 patients. Step 1 (watchful waiting) was used most frequently by 38 patients; of those, 3 chose to undergo watchful waiting for a second time. Two patients entered step 2 (self-help intervention), but neither actually started the program 
Table 1. Baseline Patient Characteristics

\begin{tabular}{|c|c|c|c|}
\hline & $\begin{array}{c}\text { Total Group }(\mathrm{N}=349) \\
n(\%)\end{array}$ & $\begin{array}{c}\text { TES Program }(n=184) \\
n(\%)\end{array}$ & $\begin{array}{c}\text { CAU }(n=165) \\
n(\%)\end{array}$ \\
\hline Mean age (SD), y & $66.1(10.2)$ & $66.25(9.8)$ & $65.84(10.6)$ \\
\hline Male & $224(64.2)$ & $113(61.4)$ & $111(67.3)$ \\
\hline Female & $125(35.8)$ & $71(38.6)$ & $54(32.3)$ \\
\hline 1 & $105(30.1)$ & $71(38.6)$ & $34(20.6)$ \\
\hline 2 & $11(3.2)$ & $6(3.3)$ & $5(3.0)$ \\
\hline Missing & $151(43.3)$ & $59(32.1)$ & $92(55.8)$ \\
\hline \multicolumn{4}{|l|}{ Primary CRC tumor location } \\
\hline \multicolumn{4}{|l|}{ Chemotherapy regimen } \\
\hline Capecitabine & $72(20.6)$ & $36(19.6)$ & $36(21.8)$ \\
\hline CAPOX & $240(68.8)$ & $124(67.4)$ & $116(70.3)$ \\
\hline FOLFOX & $24(6.9)$ & $17(9.2)$ & $7(4.2)$ \\
\hline Other & $10(2.9)$ & $6(3.3)$ & $4(2.4)$ \\
\hline Missing & $3(0.9)$ & $1(0.5)$ & $2(1.2)$ \\
\hline \multicolumn{4}{|l|}{ Marital status } \\
\hline Married/Domestic partnership & $256(73.4)$ & $133(72.3)$ & $123(74.5)$ \\
\hline Unmarried/Divorced/Widowed & $89(25.5)$ & $49(26.6)$ & $40(24.2)$ \\
\hline \multicolumn{4}{|l|}{ Currently working } \\
\hline Yes & $81(23.2)$ & $39(21.2)$ & $42(25.5)$ \\
\hline No/Retired & $264(75.6)$ & $143(77.7)$ & $121(73.3)$ \\
\hline Missing & $4(1.1)$ & $2(1.1)$ & $2(1.2)$ \\
\hline \multicolumn{4}{|c|}{ Time from diagnosis of primary tumor until start of study } \\
\hline$<1.5 \mathrm{mo}$ & $116(33.2)$ & $52(28.3)$ & $64(38.8)$ \\
\hline $1.5-10.0 \mathrm{mo}$ & $114(32.9)$ & $66(35.9)$ & $48(29.1)$ \\
\hline$>10.0 \mathrm{mo}$ & $116(33.2)$ & $65(35.3)$ & $51(30.9)$ \\
\hline Missing & $3(0.9)$ & $1(0.5)$ & $2(1.2)$ \\
\hline \multicolumn{4}{|l|}{ Distress } \\
\hline Mean HADS score (SD) & $9.52(6.6)$ & $8.8(6.5)$ & $10.3(6.7)$ \\
\hline
\end{tabular}

(continued on next page)

Abbreviations: CAPOX, capecitabine/oxaliplatin; CAU, care as usual; CRC, colorectal cancer; FOLFOX, leucovorin/5-fluorouracil/oxaliplatin; HADS, Hospital Anxiety and Depression Scale; PS, performance status; QLQ-C30, QoL of Cancer Patients questionnaire; QoL, quality of life; TES, targeted selection (T), enhanced care (E), and referral to well-described effective interventions using a stepped care-oriented approach (S). 


\begin{tabular}{|c|c|c|c|}
\hline & $\begin{array}{c}\text { Total Group (N=349) } \\
n(\%)\end{array}$ & $\underset{n(\%)}{\text { TES Program }}(n=184)$ & $\begin{array}{c}\text { CAU }(n=165) \\
n(\%)\end{array}$ \\
\hline \multicolumn{4}{|c|}{ Mean QoL (EORTC QLQ-C30) scores (SD) } \\
\hline Physical functioning & $74.4(20.6)$ & $76.0(20.9)$ & $72.6(20.2)$ \\
\hline Role functioning & $64.3(30.7)$ & $68.3(28.9)$ & $59.8(32.0)$ \\
\hline Emotional functioning & $77.1(18.9)$ & $78.3(18.1)$ & $75.9(19.8)$ \\
\hline Cognitive functioning & $88.9(15.4)$ & $89.8(14.2)$ & $88.0(16.5)$ \\
\hline Social functioning & $76.2(25.8)$ & $79.3(23.8)$ & $72.8(27.5)$ \\
\hline Global QoL & $63.0(21.8)$ & $64.9(22.0)$ & $60.9(21.3)$ \\
\hline
\end{tabular}

Abbreviations: CAPOX, capecitabine/oxaliplatin; CAU, care as usual; CRC, colorectal cancer; FOLFOX, leucovorin/5-fluorouracil/oxaliplatin; HADS, Hospital Anxiety and Depression Scale; PS, performance status; QLQ-C30, QoL of Cancer Patients questionnaire; QoL, quality of life; TES, targeted selection (T), enhanced care (E), and referral to well-described effective interventions using a stepped care-oriented approach (S).

due to disease progression. Step 3 (face-to-face problemsolving treatment) was provided to 1 patient, and 18 patients were referred to specialized psychosocial care (step 4).

\section{Effectiveness of the TES Program}

Means and SDs (observed scores) of the HADS scores and secondary outcomes are summarized in supplemental eTable 4. No evidence of an intervention effect on HADS scores was seen at any time point (discrete time model; all $P>.05$; ES, $|d| \leq 0.16$ ) (Table 3, Figure 3). Similarly, the course of distress over time did not differ between patients in the TES and CAU arms (linear time model; $P=.093$; ES, $|d|=0.16$ ) (Table 3, Figure 4). For the course of secondary end points between groups over time, a positive effect on

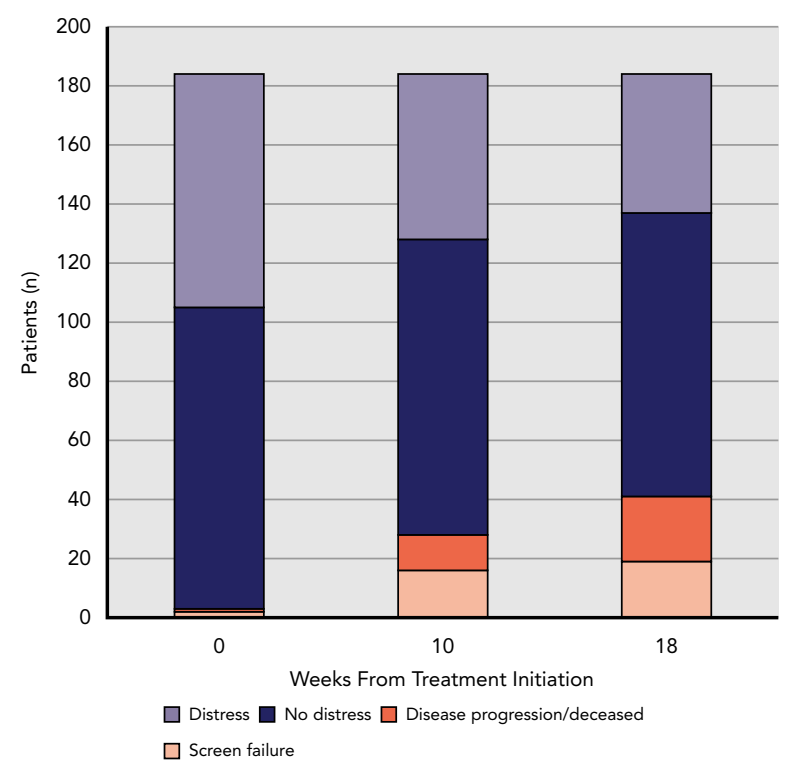

Figure 2. Distress screening with Hospital Anxiety and Depression Scale and the Distress Thermometer/Problem List in the TES arm. Abbreviation: TES, targeted selection (T), enhanced care $(E)$, and referral to welldescribed effective interventions using a stepped care-oriented approach (S). patient satisfaction $(P=.003)$ and cognitive functioning $(P=.010)$ was seen in the intervention arm (Table 3$)$. Symptoms of distress were recognized by clinicians in 79 patients $(42.9 \%)$ in the TES group and in $62(37.6 \%)$ in the control group $(P=.309)$. Additionally, no betweengroup difference was found regarding referral of distressed patients by clinicians $(P=.264)$, which was reported for 30 patients $(16.3 \%)$ in the TES group and $20(12.1 \%)$ in the control group (Table 3, supplemental eTable 4).

Sensitivity analysis conducted in 269 patients (ie, excluding patients in the CAU arm from the 3 hospitals that provided screening) showed the robustness of the primary findings. No evidence of an intervention effect on HADS scores at any time point (discrete time models; all $P>.05$; ES, $|d| \leq 0.12$ ) or on the course of distress over time (linear time model; $P=.479$; ES, $d=0.08$ ) was found (data not shown).

\section{Discussion}

This CRT showed no evidence that screening for distress and offering treatment if needed improved psychological distress in patients with mCRC. The course of distress did not differ among patients assigned to the TES group

\begin{tabular}{|lc|}
\hline Table 2. Stepped Care in TES Arm & \\
\hline Stepped Care & $\begin{array}{c}\text { TES Arm (N=184) } \\
\mathbf{n}(\%)\end{array}$ \\
\hline Watchful waiting & $27(14.7)$ \\
\hline $\begin{array}{l}\text { Active stepped care treatment } \\
\text { Self-help program }\end{array}$ & $21(11.4)$ \\
\hline Problem-solving treatment & $2(1.1)$ \\
\hline Specialized psychosocial care & $1(0.5)$ \\
\hline Total patients using stepped care & $18(9.8)$ \\
\hline
\end{tabular}

Abbreviation: TES, targeted selection $(T)$, enhanced care $(E)$, and referral to welldescribed effective interventions using a stepped care-oriented approach (S). a27 patients used watchful waiting only. In addition, 11 patients used watchful waiting in combination with another step. 


\section{Table 3. Differences in Primary and Secondary Outcomes Between Arms, From LMM Analyses}

\begin{tabular}{|c|c|c|c|c|c|c|}
\hline & \multicolumn{3}{|c|}{ Discrete Time Model } & \multicolumn{3}{|c|}{ Linear Time Model } \\
\hline & Test Statistic & $P$ Value & Effect Size ${ }^{a}(d)$ & Test Statistic & $P$ Value & Effect Size $^{a}(d)$ \\
\hline \multicolumn{7}{|l|}{ Primary outcome } \\
\hline \multicolumn{7}{|l|}{ Distress (HADS) } \\
\hline $3 \mathrm{wk}$ & $z=-0.54$ & .590 & -0.04 & & & \\
\hline $10 \mathrm{wk}$ & $z=-1.07$ & .283 & -0.10 & & & \\
\hline 24 wk & $z=-1.17$ & .240 & -0.12 & & & \\
\hline $48 w k$ & $z=-1.62$ & .104 & -0.16 & $z=-1.68$ & .093 & -0.16 \\
\hline \multicolumn{7}{|l|}{ Secondary outcomes } \\
\hline \multicolumn{7}{|c|}{ Physical functioning (EORTC QLQ-C30) } \\
\hline $10 \mathrm{wk}$ & $z=2.72$ & .006 & & & & \\
\hline 24 wk & $z=0.28$ & .779 & 0.03 & & & \\
\hline $48 w k$ & $z=1.39$ & .164 & 0.17 & $z=1.27$ & .204 & 0.15 \\
\hline \multicolumn{7}{|c|}{ Role functioning (EORTC QLQ-C30) } \\
\hline $10 w k$ & $z=0.94$ & .345 & 0.10 & & & \\
\hline 24 wk & $z=-0.22$ & .826 & -0.02 & & & \\
\hline $48 w k$ & $z=0.48$ & .630 & 0.06 & $z=0.30$ & .767 & 0.04 \\
\hline \multicolumn{7}{|c|}{ Emotional functioning (EORTC QLQ-C30) } \\
\hline $10 w k$ & $z=0.72$ & .474 & 0.07 & & & \\
\hline 24 wk & $z=1.02$ & .306 & 0.12 & & & \\
\hline $48 w k$ & $z=1.35$ & .178 & 0.17 & $z=1.36$ & .175 & 0.17 \\
\hline \multicolumn{7}{|c|}{ Cognitive functioning (EORTC QLQ-C30) } \\
\hline $10 w k$ & $z=1.98$ & .048 & 0.23 & & & \\
\hline 24 wk & $z=2.61$ & .009 & 0.34 & & & \\
\hline $48 w k$ & $z=2.09$ & .037 & 0.31 & $z=2.58$ & .010 & 0.37 \\
\hline \multicolumn{7}{|c|}{ Social functioning (EORTC QLQ-C30) } \\
\hline $10 w k$ & $z=1.33$ & .182 & 0.13 & & & \\
\hline $24 \mathrm{wk}$ & $z=0.66$ & .507 & 0.08 & & & \\
\hline $48 w k$ & $z=-0.40$ & .689 & -0.05 & $z=-0.51$ & .613 & -0.06 \\
\hline \multicolumn{7}{|c|}{ Global functioning (EORTC QLQ-C30) } \\
\hline $10 w k$ & $z=1.61$ & .107 & 0.17 & & & \\
\hline 24 wk & $z=-0.16$ & .870 & -0.02 & & & \\
\hline $48 w k$ & $z=1.74$ & .083 & 0.21 & $z=1.44$ & .149 & 0.17 \\
\hline \multicolumn{7}{|l|}{ Patient satisfaction ${ }^{\mathrm{b}}$ (CSO-8) } \\
\hline $24 w k$ & $z=0.89$ & .371 & 0.08 & & & \\
\hline $48 w k$ & $z=2.98$ & .003 & 0.31 & $z=2.99$ & .003 & 0.31 \\
\hline \multicolumn{7}{|c|}{ Recognition distress by clinicians } \\
\hline $79(42.9 \%)$ vs $62(37.6 \%)$ & $z=-1.02$ & .309 & 0.11 & & & \\
\hline \multicolumn{7}{|l|}{ Referral distress by clinicians } \\
\hline $30(16.3 \%)$ vs $20(12.1 \%)$ & $z=-1.12$ & .264 & 0.12 & & & \\
\hline
\end{tabular}

Abbreviations: CSQ-8, Client Satisfaction Questionnaire-8; HADS, Hospital Anxiety and Depression Scale; LMM, linear mixed model; QLQ-C30, QoL of Cancer Patients questionnaire.

aEffect size obtained by standardizing the group-by-time interaction term from the LMM using the pooled within-group SDs.

bOutcome variables were administered at 10, 24, and 48 weeks only and corrected for differences at 10 weeks. 


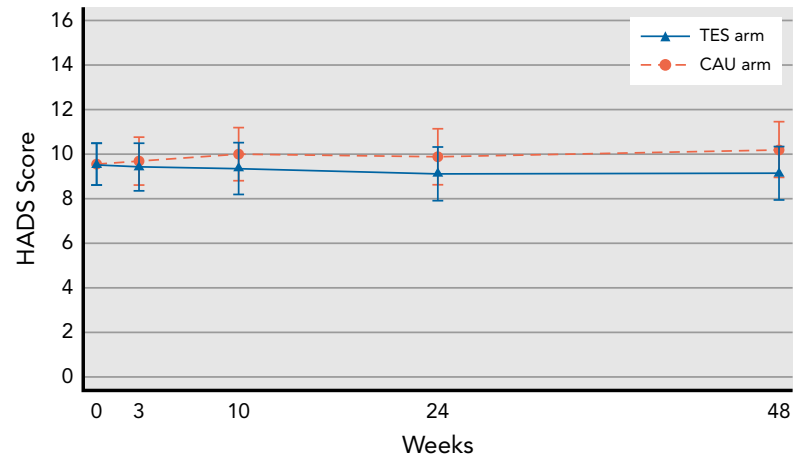

Figure 3. Predicted means of HADS score (with error bands) in the TES group (intervention) versus CAU arm (control) at the different time points in weeks from a linear mixed models analysis using a discrete time model.

Abbreviations: CAU, care as usual; HADS, Hospital Anxiety and Depression Scale; TES, targeted selection $(T)$, enhanced care $(E)$, and referral to welldescribed effective interventions using a stepped care-oriented approach (S).

versus the CAU group. Previous studies already revealed that screening alone is not enough to improve distress ${ }^{27}$ (supplemental eAppendix 1), but they suggested that screening when followed with further assessment of specific needs and appropriate referral and treatment could lead to improvement in patient outcomes. ${ }^{12,13}$ However, our results show that the combination of screening, triage, and referral to appropriate services did not result in better distress outcomes.

The absence of effect of this combined approach is most likely due to the low use of stepped care in the intervention group. In the TES arm, $26.1 \%$ of patients entered the stepped care program, with only $11.4 \%$ using genuine active treatment to address psychological distress and $14.7 \%$ using only watchful waiting. The low uptake of care, despite a rather high rate of distressed patients, is consistent with findings in other studies showing low acceptance rates of psychological treatment ranging from $3 \%$ to $10 \%{ }^{28-31}$ Empiric evidence is accumulating that an elevated level of distress does not equate to the need for support. ${ }^{16,30,31}$ Some patients needing psychological support show no signs of distress, whereas others with elevated levels of distress do not report unmet needs. ${ }^{32}$ Our results further underscore these findings and challenge the assumption that screening for distress helps ensure identification of patients in need of support. ${ }^{31,33}$ Alternatively, developing valid indicators of need for psychological treatment is an urgent research priority. ${ }^{30}$

Patients assigned to the TES group reported higher satisfaction with care and better cognitive function than those assigned to the CAU group. Additionally, patients in the TES arm tended to have better QoL scores over time than those in the CAU group, although this was not statistically significant. A plausible explanation is that

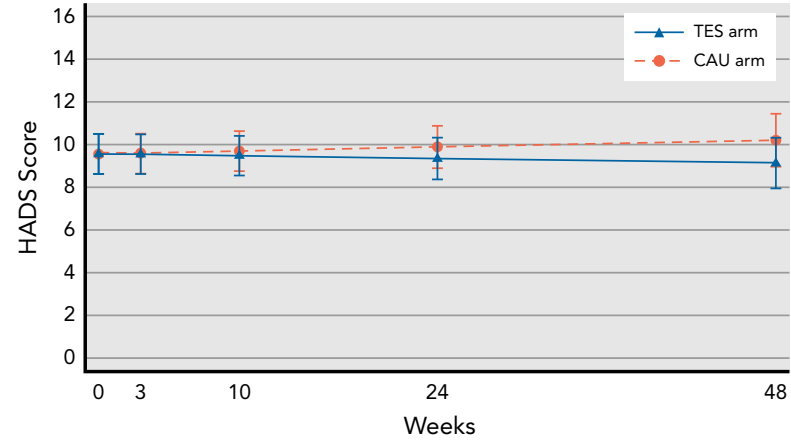

Figure 4. Predicted means of HADS score (with error bands) in the TES group (intervention) versus CAU arm (control) over time in weeks from a linear mixed models analysis using a linear time model.

Abbreviations: CAU, care as usual; HADS, Hospital Anxiety and Depression Scale; TES, targeted selection (T), enhanced care $(E)$, and referral to welldescribed effective interventions using a stepped care-oriented approach (S).

enhanced discussion of psychosocial concerns by nurses and oncologists improves well-being in patients with mCRC. It was previously suggested that, rather than implementing screening, patients could simply be asked whether they would like to discuss any psychosocial concerns with oncologic or psychosocial staff, regardless of their level of distress. ${ }^{34}$ Indeed, patients' emotional wellbeing and QoL outcomes have been shown to improve after solely evaluating psychological issues with staff. ${ }^{35}$

Our study had some limitations. First, the observed low use of the stepped care program led us to pursue the futility analysis, resulting in halted recruitment. The low uptake of psychological treatment, which is consistent with findings in other studies (see earlier discussion), resulted in a small overall ES of routine screening and subsequently offering treatment if indicated. Our results show that only a very large trial would be sufficiently powered to detect the small overall effect. One might question the clinical relevance of such a modest effect. Second, it has been shown that the HADS is effective in detecting clinically significant elevations of distress in oncology populations, ${ }^{15}$ it was recently shown that a range of psychosocial concerns are not covered by the HADS. ${ }^{36}$ However, our study used the DT/PL in addition to the HADS, and trained nurses evaluated all screening results with patients, allowing detection of additional patients in need of psychosocial care not identified by the HADS or the DT/PL. Furthermore, $60 \%$ of patients in the TES arm were identified as having elevated distress, which is considerably higher than percentages reported in previous studies ${ }^{16,37}$; however, this could have been partly the result of the relatively low cutoff that was set for the HADS score $(\geq 13)$; reported cutoff scores on the HADS vary greatly among studies in cancer settings (from $\geq 10$ to $\geq 16$ ). ${ }^{38}$ 
Another possible limitation could be the homogeneity of our study population. Cancer type-specific characteristics (eg, average age at disease onset, disease course, and associated physical impairment) may influence patients' level of distress and their response to supportive psychological interventions. However, the combination of screening followed by a subsequent treatment program has also not been found to improve patient outcomes in patients with different tumor types or stages (supplemental eAppendix 1).

Strengths of our study were that it was conducted in 16 oncology departments at different hospitals and a cluster random design was used, which minimized the risk of contamination. Furthermore, we created optimal conditions for a standardized screening and referral program, with marked contrasts between the intervention and CAU arms. Our findings showed that $89 \%$ of planned screenings and evaluations were indeed performed, indicating successful intervention delivery in the TES arm..$^{39}$ The high protocol adherence enhanced the likelihood of finding differences in distress over time between the arms. Of the 8 hospitals assigned to CAU, 3 offered routine screening for psychological distress (without standardized follow-up and algorithms to guide triage), and the sensitivity analysis excluding patients enrolled in these hospitals yielded results similar to those in the primary analysis, thereby strengthening our conclusion and confirming its robustness. Another strength of this trial was the timing and multiple time points of screening (eg, at start of treatment and after 10 and 18 weeks). Previous intervention studies offering screening and subsequent treatment were designed to screen and treat directly at diagnosis ${ }^{29}$ or only once, ${ }^{40}$ whereas the importance of monitoring emotional problems and distress over time has been highlighted. ${ }^{41}$

\section{Conclusions}

Due to the low uptake of active treatment in the TES group, we found no evidence that screening for distress and offering subsequent treatment improve psychological distress. Our findings, however, suggest that enhanced discussion of psychosocial concerns may improve aspects of patient well-being.

Submitted September 3, 2018; accepted for publication February 20, 2019

Author contributions: Study concept: Schuurhuizen, Braamse, Beekman, Cuijpers, Hoogendoorn, Konings, Verheul, Dekker. Study design: Braamse, Beekman, M.H.M. van der Linden, Hoogendoorn, Konings, Verheul, Dekker Data acquisition: Sommeijer, Lustig, Vrijaldenhoven, Bloemendal, van Groeningen, van Zweeden, van der Vorst, Rietbroek, Tromp-van Driel, Wymenga, M.H.L. van der Linden, Beeker, Polee, Batman, Los, Boschove, Brakenhoff, Konings, Verheul. Quality control of data and algorithms: Hoogendoorn, Berkhof. Data analysis and interpretation: Schuurhuizen, Braamse, Hoogendoorn, Berkhof, Konings, Verheul, Dekker. Statistical analysis: Schuurhuizen, Braamse, Hoogendoorn, Berkhof, Dekker. Manuscript preparation: Schuurhuizen, Braamse, Hoogendoorn, Konings, Verheul, Dekker. Manuscript review and editing: All authors.

Disclosures: The authors have disclosed that they have not received any financial considerations from any person or organization to support the preparation, analysis, results, or discussion of this article.

Funding: This work was supported by a grant from the Dutch Cancer Society-Alpe d'Huzes (VU 2011-5279).

Correspondence: Joost Dekker, PhD, Department of Psychiatry, VU University Medical Center, Cancer Center Amsterdam, PO Box 7057, 1007MB, Amsterdam, the Netherlands. Email: j.dekker@vumc.nl

\section{References}

1. Bultz BD, Carlson LE. Emotional distress: the sixth vital sign in cancer care. J Clin Oncol 2005;23:6440-6441.

2. Holland JC, Deshields TL, Andersen B, et al. NCCN Clinical Practice Guidelines in Oncology: Distress Management. Version 2.2018. Accessed August 1, 2018. To view the most recent version, visit NCCN.org.

3. Quinten C, Coens C, Mauer M, et al. Baseline quality of life as a prognostic indicator of survival: a meta-analysis of individual patient data from EORTC clinical trials. Lancet Oncol 2009;10:865-871.

4. DiMatteo MR, Lepper HS, Croghan TW. Depression is a risk factor for noncompliance with medical treatment: meta-analysis of the effects of anxiety and depression on patient adherence. Arch Intern Med 2000;160:2101-2107.

5. Brown KW, Levy AR, Rosberger Z, et al. Psychological distress and cancer survival: a follow-up 10 years after diagnosis. Psychosom Med 2003;65: 636-643.

6. Institute of Medicine Committee on Psychosocial Services to Cancer Patients/Families in a Community Setting; Adler NE, Page AE, eds. Cancer Care for the Whole Patient: Meeting Psychosocial Health Needs. Washington, DC: National Academies Press; 2008.

7. Faller $\mathrm{H}$, Schuler M, Richard M, et al. Effects of psycho-oncologic interventions on emotional distress and quality of life in adult patients with cancer: systematic review and meta-analysis. J Clin Oncol 2013;31:782-793.

8. Nezu AM, Nezu CM, Felgoise SH, et al. Project Genesis: assessing the efficacy of problem-solving therapy for distressed adult cancer patients. J Consult Clin Psychol 2003;71:1036-1048.

9. Clark PG, Bolte S, Buzaglo J, et al. From distress guidelines to developing models of psychosocial care: current best practices. J Psychosoc Oncol 2012;30:694-714
10. Fawzy FI, Fawzy NW, Arndt LA, et al. Critical review of psychosocial interventions in cancer care. Arch Gen Psychiatry 1995;52:100-113.

11. Lutgendorf SK, De Geest K, Bender D, et al. Social influences on clinical outcomes of patients with ovarian cancer. J Clin Oncol 2012;30: 2885-2890.

12. Merckaert I, Libert $Y$, Messin S, et al. Cancer patients' desire for psychological support: prevalence and implications for screening patients' psychological needs. Psychooncology 2010;19:141-149.

13. Carlson LE. Screening alone is not enough: the importance of appropriate triage, referral, and evidence-based treatment of distress and common problems. J Clin Oncol 2013;31:3616-3617.

14. Schuurhuizen CS, Braamse AM, Beekman AT, et al. Screening and treatment of psychological distress in patients with metastatic colorectal cancer: study protocol of the TES trial. BMC Cancer 2015;15: 302.

15. Singer S, Kuhnt S, Götze H, et al. Hospital Anxiety and Depression Scale cutoff scores for cancer patients in acute care. Br J Cancer 2009;100: 908-912.

16. Tuinman MA, Gazendam-Donofrio SM, Hoekstra-Weebers JE. Screening and referral for psychosocial distress in oncologic practice: use of the Distress Thermometer. Cancer 2008;113:870-878.

17. Donovan KA, Grassi L, McGinty HL, et al. Validation of the Distress Thermometer worldwide: state of the science. Psychooncology 2014;23 241-250.

18. Krebber AM, Leemans $C R$, de Bree $R$, et al. Stepped care targeting psychological distress in head and neck and lung cancer patients: a randomized clinical trial. BMC Cancer 2012;12:173. 
19. Zigmond AS, Snaith RP. The Hospital Anxiety and Depression Scale. Acta Psychiatr Scand 1983;67:361-370.

20. Krebber AM, Jansen $\mathrm{F}$, Witte Bl, et al. Stepped care targeting psychological distress in head and neck cancer and lung cancer patients: a randomized, controlled trial. Ann Oncol 2016;27:1754-1760.

21. Aaronson NK, Ahmedzai S, Bergman B, et al. The European Organization for Research and Treatment of Cancer QLQ-C30: a quality-of-life instrument for use in international clinical trials in oncology. J Natl Cancer Inst 1993;85:365-376.

22. de Brey $\mathrm{H}$. A cross-national validation of the client satisfaction questionnaire: the Dutch experience. Eval Program Plann 1983;6: 395-400.

23. Malouff JM, Thorsteinsson EB, Schutte NS. The efficacy of problem solving therapy in reducing mental and physical health problems: a metaanalysis. Clin Psychol Rev 2007;27:46-57.

24. Hemming K, Marsh J. A menu-driven facility for sample-size calculations in cluster randomized controlled trials. Stata J 2013; 13:114-135.

25. Fitzmaurice GM, Laird NM, Ware $\mathrm{JH}$. Modelling the mean: analyzing response profiles. In: Applied Longitudinal Analysis. Hoboken, NJ: John Wiley \& Sons; 2004:103-140.

26. Morris SB. Estimating effect sizes from pretest-posttest-control group designs. Organ Res Methods 2007;11:364-386.

27. Meijer A, Roseman M, Delisle VC, et al. Effects of screening for psychological distress on patient outcomes in cancer: a systematic review. J Psychosom Res 2013;75:1-17

28. Funk R, Cisneros C, Williams RC, et al. What happens after distress screening? Patterns of supportive care service utilization among oncology patients identified through a systematic screening protocol. Support Care Cancer 2016;24:2861-2868.

29. Braamse AM, van Meijel B, Visser OJ, et al. A randomized clinical trial on the effectiveness of an intervention to treat psychological distress and improve quality of life after autologous stem cell transplantation. Ann Hematol 2016:95:105-114.
30. Dekker J, Braamse A, Schuurhuizen C, et al. Distress in patients with cancer - on the need to distinguish between adaptive and maladaptive emotional responses. Acta Oncol 2017;56:1026-1029.

31. van Scheppingen C, Schroevers MJ, Pool G, et al. Is implementing screening for distress an efficient means to recruit patients to a psychological intervention trial? Psychooncology 2014;23:516-523.

32. Brebach R, Sharpe L, Costa DS, et al. Psychological intervention targeting distress for cancer patients: a meta-analytic study investigating uptake and adherence. Psychooncology 2016;25:882-890.

33. Howell D, Olsen K. Distress-the 6th vital sign. Curr Oncol 2011;18:208-210.

34. Palmer SC, van Scheppingen C, Coyne JC. Clinical trial did not demonstrate benefits of screening patients with cancer for distress. J Clin Oncol 2011;29:e277-280.

35. Velikova G, Brown JM, Smith AB, et al. Computer-based quality of life questionnaires may contribute to doctor-patient interactions in oncology. $\mathrm{Br}$ J Cancer 2002;86:51-59.

36. Thalén-Lindström AM, Glimelius BG, Johansson BB. Identification of distress in oncology patients: a comparison of the Hospital Anxiety and Depression Scale and a thorough clinical assessment. Cancer Nurs 2016;39:E31-E39.

37. Zabora J, BrintzenhofeSzoc K, Curbow B, et al. The prevalence of psychological distress by cancer site. Psychooncology 2001;10:19-28.

38. Mitchell AJ, Meader N, Symonds P. Diagnostic validity of the Hospital Anxiety and Depression Scale (HADS) in cancer and palliative settings: a meta-analysis. J Affect Disord 2010;126:335-348.

39. Lawton J, Jenkins N, Darbyshire JL, et al. Challenges of maintaining research protocol fidelity in a clinical care setting: a qualitative study of the experiences and views of patients and staff participating in a randomized controlled trial. Trials 2011;12:108.

40. Chambers SK, Girgis A, Occhipinti S, et al. A randomized controlled trial of psychological intervention for high distress cancer patients and carers [abstract]. Psychooncology 2014;23(Suppl 1):47-48.

41. Bevans M. Health-related quality of life following allogeneic hematopoietic stem cell transplantation. Hematology Am Soc Hematol Educ Program 2010;2010:248-254. 
Supplemental online content for:

\section{Screening and Stepped Care Targeting Psychological Distress in Patients With Metastatic Colorectal Cancer: The TES Cluster Randomized Trial}

Claudia S.E.W. Schuurhuizen, MD; Annemarie M.J. Braamse, PhD; Aartjan T.F. Beekman, PhD; Pim Cuijpers, PhD; Mecheline H.M. van der Linden, PhD; Adriaan W. Hoogendoorn, PhD; Hans Berkhof, PhD;

Dirkje W. Sommeijer, MD, PhD; Vera Lustig, MD; Suzan Vrijaldenhoven, MD, PhD; Haiko J. Bloemendal, MD, PhD; Cees J. van Groeningen, MD, PhD; Annette A. van Zweeden, MD; Maurice J.D.L. van der Vorst, MD;

Ron Rietbroek, MD; Cathrien S. Tromp-van Driel, MD; Machteld N.W. Wymenga, MD, PhD;

Peter W. van der Linden, MD, PhD; Aart Beeker, MD; Marco B. Polee, MD, PhD; Erdogan Batman, MD; Maartje Los, MD, PhD; Aart van Bochove, MD; Jan A.C. Brakenhoff, MD; Inge R.H.M. Konings, MD, PhD; Henk M.W. Verheul, MD, PhD; and Joost Dekker, PhD

J Natl Compr Canc Netw 2019;17(8):911-920

eTable 1: Characteristics and Outcomes of the Included Randomized Controlled Trials

eTable 2: Conditional Power and Required Number of Patients to Obtain Power of 0.80

eTable 3: Extended Baseline Patient Characteristics

eTable 4: Mean Observed Scores for Outcomes

eAppendix 1: Review: Evaluation of Distress Screening on Psychological Well-Being 


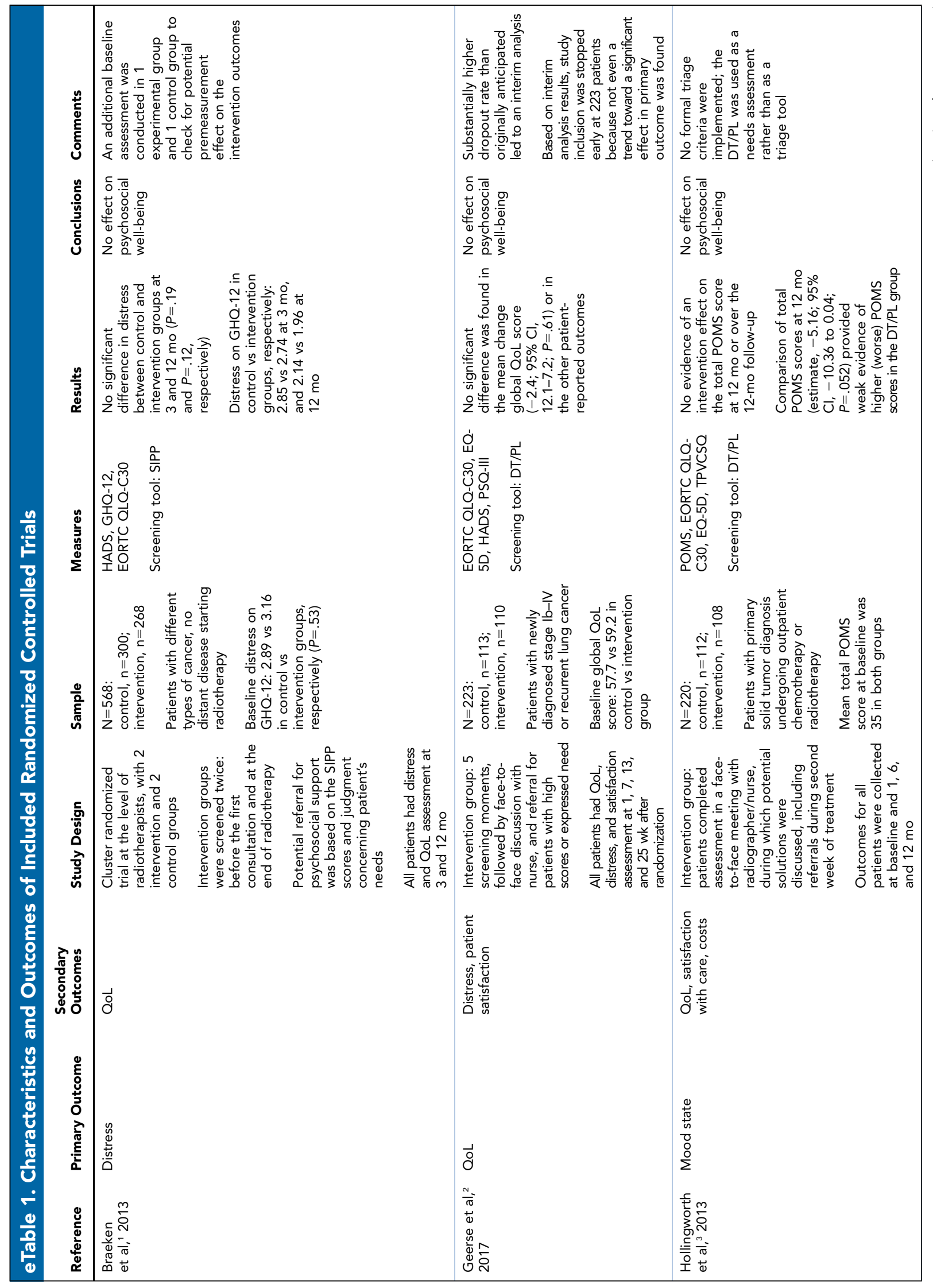

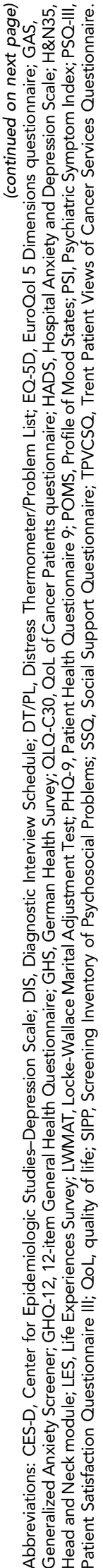



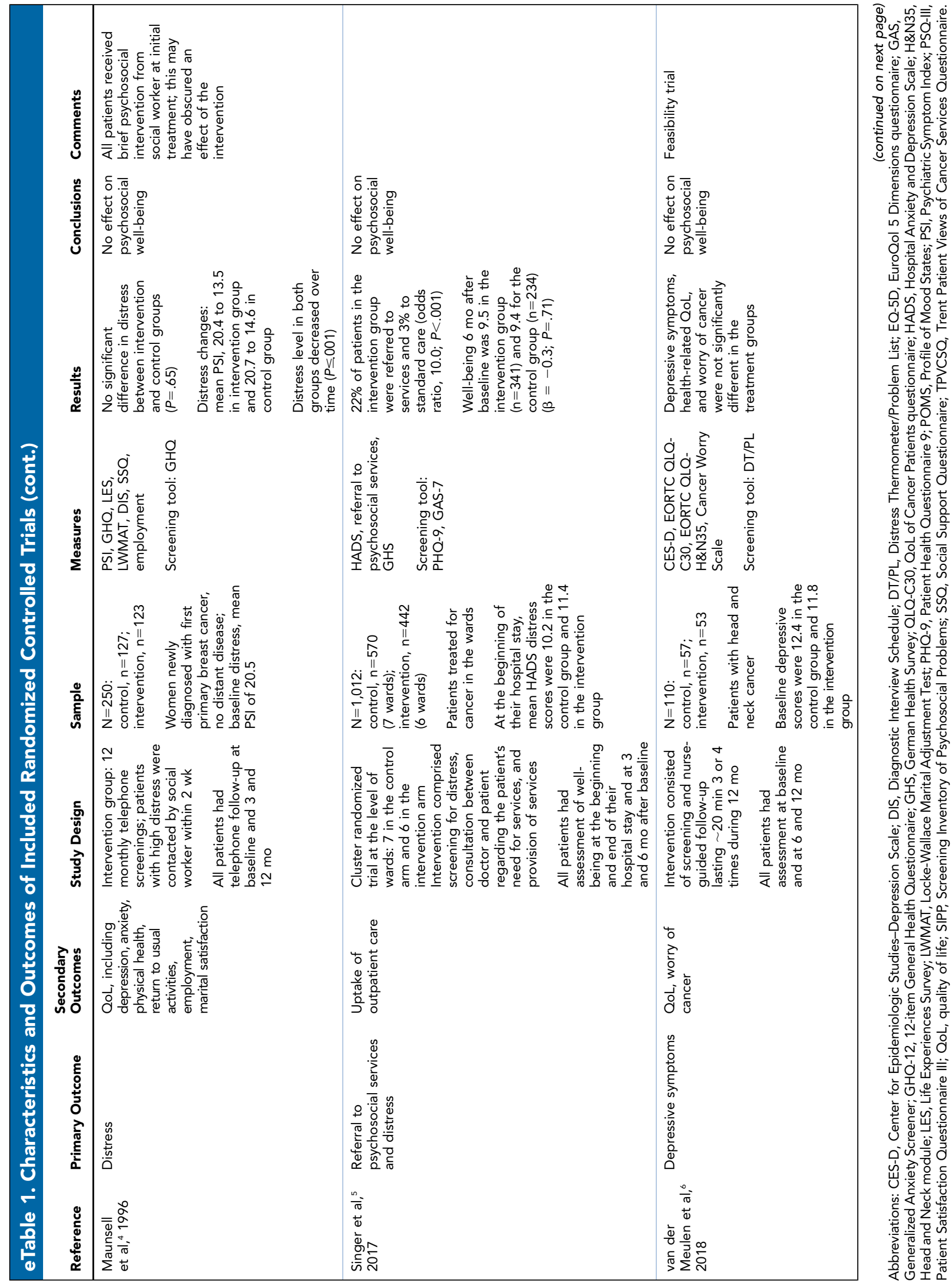

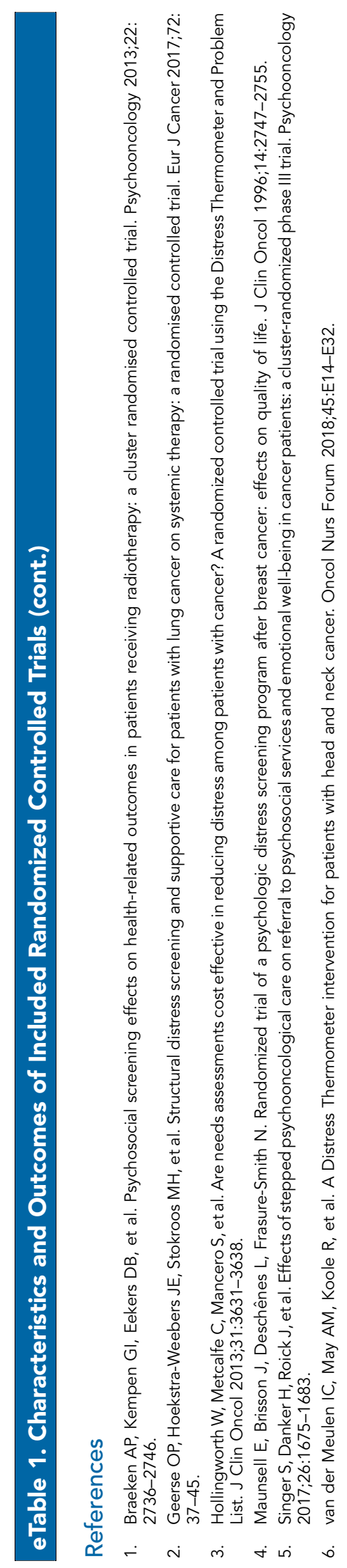


\section{eTable 2. Conditional Power and Required Number of Patients to Obtain Power of 0.80}

Proportion Receiving Distress Treatment in

TES Program (\%)

Conditional Power With $n=715$

Number Needed (Experimental + Control

Groups) for Power of 0.80

\begin{tabular}{|llr|}
\hline $5 \%$ & 0.06 & 251,088 \\
\hline $8.7 \%^{\mathrm{a}}$ & 0.11 & 33,318 \\
$10 \%$ & 0.13 & 20,716 \\
\hline $13.7 \%^{\mathrm{b}}$ & 0.21 & 7,548 \\
\hline $15 \%$ & 0.24 & 5,746 \\
$15.4 \%^{\mathrm{c}}$ & 0.25 & 5,318 \\
\hline $20 \%$ & 0.39 & 2,552 \\
\hline $25 \%$ & 0.56 & 1,432 \\
$33 \%$ & 0.80 & 716 \\
$35 \%$ & 0.84 & 640 \\
\hline
\end{tabular}

Abbreviation: TES, targeted selection (T), enhanced care (E), and referral to well-described effective interventions using a stepped care-oriented approach (S).

abserved proportion of patients treated for psychologic distress.

bUpper limit of the $95 \% \mathrm{Cl}$ of the observed proportion treated.

upper limit of the $99 \% \mathrm{Cl}$ of the observed proportion treated. 


\section{eTable 3. Extended Baseline Patient Characteristics}

\begin{tabular}{|c|c|c|c|}
\hline & $\begin{array}{c}\text { Total Group ( } N=349) \\
n(\%)\end{array}$ & $\begin{array}{c}\text { TES Program } \\
n(\%)\end{array}$ & $\begin{array}{c}\text { CAU }(n=165) \\
n(\%)\end{array}$ \\
\hline Mean age (SD), y & $66.1(10.2)$ & $66.25(9.8)$ & $65.84(10.6)$ \\
\hline Male & $224(64.2)$ & $113(61.4)$ & $111(67.3)$ \\
\hline Female & $125(35.8)$ & $71(38.6)$ & $54(32.7)$ \\
\hline 1 & $105(30.1)$ & 71 (38.6) & $34(20.6)$ \\
\hline 2 & $11(3.2)$ & $6(3.3)$ & $5(3.0)$ \\
\hline Missing & $151(43.3)$ & $59(32.1)$ & $92(55.8)$ \\
\hline \multicolumn{4}{|l|}{ Primary tumor location } \\
\hline \multicolumn{4}{|l|}{ RAS status } \\
\hline WT & $62(17.8)$ & $31(16.8)$ & $31(18.8)$ \\
\hline MT & $86(24.6)$ & $49(26.6)$ & $37(22.4)$ \\
\hline Missing & $201(57.6)$ & $104(56.5)$ & $97(58.8)$ \\
\hline \multicolumn{4}{|l|}{ Chemotherapy regimen } \\
\hline Capecitabine & $72(20.6)$ & $36(19.6)$ & $36(21.8)$ \\
\hline CAPOX & $240(68.8)$ & $124(67.4)$ & $116(70.3)$ \\
\hline FOLFOX & $24(6.9)$ & $17(9.2)$ & $7(4.2)$ \\
\hline Other & $10(2.9)$ & $6(3.3)$ & $4(2.4)$ \\
\hline \multicolumn{4}{|l|}{ Marital status } \\
\hline Married/Domestic partnership & $256(73.4)$ & $133(72.3)$ & $123(74.5)$ \\
\hline Unmarried/Divorced/Widowed & $89(25.5)$ & $49(26.6)$ & $40(24.2)$ \\
\hline Missing & $4(1.1)$ & $2(1.1)$ & $2(1.2)$ \\
\hline \multicolumn{4}{|l|}{ Education } \\
\hline Low & $19(5.4)$ & $10(5.4)$ & $9(5.5)$ \\
\hline Middle & $223(63.9)$ & $122(66.3)$ & $101(61.2)$ \\
\hline High & $101(28.9)$ & 49 (26.6) & $52(31.5)$ \\
\hline Missing & $6(1.7)$ & $3(1.6)$ & $3(1.8)$ \\
\hline
\end{tabular}

(continued on next page)

Abbreviations: CAPOX, capecitabine and oxaliplatin; CAU, care as usual; FOLFOX, leucovorin/5-fluorouracil/oxaliplatin; HADS, Hospital Anxiety and Depression Scale; HIPEC, hyperthermic intraperitoneal chemotherapy; MT, mutant type; PS, performance status; QLQ-C30, QoL of Cancer Patients questionnaire; QoL, quality of life; RFA, radiofrequency ablation; TES, targeted selection (T), enhanced care (E), and referral to well-described effective interventions using a stepped care-oriented approach (S); WT, wild type. 


\section{eTable 3. Extended Baseline Patient Characteristics (cont.)}

\begin{tabular}{|c|c|c|c|}
\hline & $\begin{array}{c}\text { Total Group (N=349) } \\
n(\%)\end{array}$ & $\underset{n(\%)}{\text { TES Program }}(n=184)$ & $\begin{array}{c}\mathrm{CAU}(n=165) \\
n(\%)\end{array}$ \\
\hline \multicolumn{4}{|l|}{ Currently working } \\
\hline Yes & $81(23.2)$ & $39(21.2)$ & $42(25.5)$ \\
\hline No/Retired & $264(75.6)$ & $143(77.7)$ & $121(73.3)$ \\
\hline Missing & $4(1.1)$ & $2(1.1)$ & $2(1.2)$ \\
\hline \multicolumn{4}{|l|}{ Nicotine use } \\
\hline No & $126(36.1)$ & $68(37.0)$ & $58(35.2)$ \\
\hline Missing & $4(1.1)$ & $2(1.1)$ & $2(1.2)$ \\
\hline \multicolumn{4}{|l|}{ Alcohol use } \\
\hline Yes & $200(57.3)$ & $103(56.0)$ & $97(58.8)$ \\
\hline $1.5-10.0 \mathrm{mo}$ & $114(32.9)$ & $66(35.9)$ & $48(29.1)$ \\
\hline$>10.0 \mathrm{mo}$ & $116(33.2)$ & $65(35.3)$ & $51(30.9)$ \\
\hline Missing & $3(0.9)$ & $1(0.5)$ & $2(1.2)$ \\
\hline \multicolumn{4}{|l|}{ Prior cancer-related treatment } \\
\hline No & $108(30.9)$ & $57(31.0)$ & $51(30.9)$ \\
\hline Yes, surgery & $215(61.6)$ & $119(64.7)$ & $96(58.2)$ \\
\hline Yes, neoadjuvant systemic therapy & $31(8.9)$ & $18(9.8)$ & $13(7.9)$ \\
\hline Yes, radiotherapy & $42(12.0)$ & $18(9.8)$ & $24(14.5)$ \\
\hline Yes, chemoradiation & $25(7.2)$ & $13(7.1)$ & $12(7.3)$ \\
\hline Surgery & $57(16.3)$ & $36(19.6)$ & $21(12.7)$ \\
\hline Chemoradiation & $2(0.6)$ & $2(1.1)$ & - \\
\hline HIPEC & $13(3.7)$ & $12(6.5)$ & $1(0.6)$ \\
\hline RFA & $12(3.4)$ & $10(5.4)$ & $2(1.2)$ \\
\hline Missing & $3(0.9)$ & $1(0.5)$ & $2(1.2)$ \\
\hline Median number of organs with metastases & 2 & 2 & 2 \\
\hline \multicolumn{4}{|l|}{ Metastases } \\
\hline Liver & $261(74.8)$ & $136(73.9)$ & $125(75.8)$ \\
\hline Lung & $146(41.8)$ & $78(42.4)$ & $68(41.2)$ \\
\hline Lymph nodes & $138(39.5)$ & $67(36.4)$ & $71(43.0)$ \\
\hline Peritoneala & 90 (25.9) & 57 (31.0) & $33(20.0)$ \\
\hline
\end{tabular}

(continued on next page)

Abbreviations: CAPOX, capecitabine and oxaliplatin; CAU, care as usual; FOLFOX, leucovorin/5-fluorouracil/oxaliplatin; HADS, Hospital Anxiety and Depression Scale; HIPEC, hyperthermic intraperitoneal chemotherapy; MT, mutant type; PS, performance status; QLQ-C30, QoL of Cancer Patients questionnaire; QoL, quality of life; RFA, radiofrequency ablation; TES, targeted selection (T), enhanced care (E), and referral to well-described effective interventions using a stepped care-oriented approach (S); WT, wild type. 


\section{eTable 3. Extended Baseline Patient Characteristics (cont.)}

\begin{tabular}{|c|c|c|c|}
\hline & $\begin{array}{c}\text { Total Group }(\mathbf{N}=349) \\
n(\%)\end{array}$ & $\begin{array}{c}\text { TES Program }(n=184) \\
n(\%)\end{array}$ & $\begin{array}{c}\text { CAU }(n=165) \\
n(\%)\end{array}$ \\
\hline Median number of metastases & 12 & 10 & 13 \\
\hline \multicolumn{4}{|l|}{ Distress } \\
\hline Mean HADS score (SD) & $9.52(6.6)$ & $8.8(6.5)$ & $10.3(6.7)$ \\
\hline \multicolumn{4}{|c|}{ Mean QoL (EORTC QLQ-C30) scores (SD) } \\
\hline Physical functioning & $74.4(20.6)$ & $76.0(20.9)$ & $72.6(20.2)$ \\
\hline Role functioning & $64.3(30.7)$ & $68.3(28.9)$ & $59.8(32.0)$ \\
\hline Emotional functioning & $77.1(18.9)$ & $78.3(18.1)$ & $75.9(19.8)$ \\
\hline Cognitive functioning & $88.9(15.4)$ & $89.8(14.2)$ & $88.0(16.5)$ \\
\hline Social functioning & $76.2(25.8)$ & $79.3(23.8)$ & $72.8(27.5)$ \\
\hline Global QoL & $63.0(21.8)$ & $64.9(22.0)$ & $60.9(21.3)$ \\
\hline
\end{tabular}

Abbreviations: CAPOX, capecitabine and oxaliplatin; CAU, care as usual; FOLFOX, leucovorin/5-fluorouracil/oxaliplatin; HADS, Hospital Anxiety and Depression Scale; HIPEC, hyperthermic intraperitoneal chemotherapy; MT, mutant type; PS, performance status; QLQ-C30, QoL of Cancer Patients questionnaire; QoL, quality of life; RFA, radiofrequency ablation; TES, targeted selection (T), enhanced care (E), and referral to well-described effective interventions using a stepped care-oriented approach (S); WT, wild type. 


\section{eTable 4. Mean Observed Scores for Outcomes}

TES Program CAU

Mean (SD) Mean (SD)

\section{Primary outcome}

Distress (HADS)

\begin{tabular}{lll} 
T0 & $8.8(6.5)$ & $10.3(6.7)$ \\
\hline T1 & $8.7(6.2)$ & $10.2(7.0)$ \\
\hline T2 & $8.4(6.6)$ & $10.4(7.6)$ \\
\hline T3 & $8.0(6.9)$ & $9.9(7.2)$ \\
\hline T4 & $7.8(6.0)$ & $9.8(7.3)$
\end{tabular}

Secondary outcomes

Physical functioning (EORTC QLQ-C30)

\begin{tabular}{lll}
\hline T0 & $76.0(20.9)$ & $72.6(20.2)$ \\
\hline T2 & $75.3(19.8)$ & $67.1(22.6)$ \\
\hline T3 & $73.5(21.9)$ & $71.9(21.3)$ \\
\hline T4 & $76.7(18.8)$ & $71.9(22.0)$
\end{tabular}

Role functioning (EORTC QLQ-C30)

\begin{tabular}{lll}
\hline T0 & $68.3(28.9)$ & $59.8(32.0)$ \\
T2 & $64.9(30.5)$ & $55.6(30.5)$ \\
\hline T3 & $68.0(29.6)$ & $63.7(28.4)$ \\
\hline T4 & $71.5(27.1)$ & $65.3(31.5)$
\end{tabular}

Emotional functioning (EORTC QLQ-C30)

\begin{tabular}{lll}
\hline T0 & $78.3(18.1)$ & $75.9(19.8)$ \\
\hline T2 & $81.8(17.8)$ & $79.3(20.2)$ \\
\hline T3 & $80.6(20.7)$ & $77.7(20.8)$ \\
T4 & $83.8(16.8)$ & $80.2(21.9)$
\end{tabular}

Cognitive functioning (EORTC QLQ-C30)

\begin{tabular}{lll}
\hline T0 & $89.8(14.2)$ & $88.0(16.5)$ \\
\hline T2 & $86.3(17.6)$ & $81.6(21.7)$ \\
\hline T3 & $86.9(17.3)$ & $81.3(20.6)$ \\
\hline T4 & $87.0(17.3)$ & $82.8(18.3)$ \\
\hline T0 & & \\
\hline T2 & $79.3(23.8)$ & $72.8(27.5)$ \\
\hline T3 & $79.4(22.4)$ & $71.7(28.0)$ \\
\hline T4 & $79.1(24.7)$ & $74.2(25.7)$ \\
\hline
\end{tabular}

(continued)

Data are presented for patients that completed the questionnaires in the TES program arm at T0 $(n=182)$, T1 $(n=173)$, T2 $(n=155)$, T3 $(n=140)$, and T4 $(n=110)$ and in the CAU arm at T0 $(n=163)$, T1 $(n=151)$, T2 $(n=137)$, T3 $(n=109)$, and T4 $(n=87)$. Data are not corrected for clustering and baseline differences.

Abbreviations: CAU, care as usual; CSQ-8, Client Satisfaction Questionnaire-8; HADS, Hospital Anxiety and Depression Scale; QLQ-C30, QoL of Cancer Patients questionnaire; $\mathrm{QoL}$, quality of life; T0, baseline; T1, shortly after the start of treatment; T2, 10 weeks after start of treatment; T3, 24 weeks after start of treatment; T4, 48 weeks after start of treatment; TES, targeted selection (T), enhanced care $(E)$, and referral to well-described effective interventions using a stepped care-oriented approach (S).

\section{eTable 4. Mean Observed Scores for Outcomes} (cont.)

\begin{tabular}{|lcc|}
\hline \multicolumn{1}{|c|}{ (cont.) } & $\begin{array}{c}\text { TES Program } \\
\text { Mean (SD) }\end{array}$ & $\begin{array}{c}\text { CAU } \\
\text { Mean (SD) }\end{array}$ \\
\hline $\begin{array}{l}\text { Secondary outcomes (cont.) } \\
\text { Global QoL (EORTC QLQ-C30) }\end{array}$ & \\
\hline T0 & $64.9(22.0)$ & $60.9(21.3)$ \\
\hline T2 & $68.5(21.5)$ & $61.8(22.6)$ \\
\hline T3 & $68.1(21.3)$ & $66.7(20.4)$ \\
\hline T4 & $72.5(16.8)$ & $65.7(22.3)$ \\
\hline Patient satisfaction (CSQ-8) & & \\
\hline T2 & $25.5(5.6)$ & $25.0(5.5)$ \\
\hline T3 & $25.7(6.0)$ & $25.2(5.3)$ \\
\hline T4 & $26.2(5.4)$ & $25.0(5.3)$ \\
\hline $\begin{array}{l}\text { Recognition of distress by } \\
\text { clinicians, } n \text { (\%) }\end{array}$ & $79(42.9 \%)$ & $62(37.6 \%)$ \\
\hline Referral for distress by clinicians, $n$ (\%) & $30(16.3 \%)$ & $20(12.1 \%)$ \\
\hline
\end{tabular}

Data are presented for patients that completed the questionnaires in the TES program arm at T0 $(n=182)$, T1 $(n=173)$, T2 $(n=155)$, T3 $(n=140)$, and T4 $(n=110)$ and in the CAU arm at T0 $(n=163)$, T1 $(n=151)$, T2 $(n=137)$, T3 $(n=109)$, and T4 $(n=87)$. Data are not corrected for clustering and baseline differences.

Abbreviations: CAU, care as usual; CSQ-8, Client Satisfaction Questionnaire-8; HADS, Hospital Anxiety and Depression Scale; QLQ-C30, QoL of Cancer Patients questionnaire; $\mathrm{CoL}$, quality of life; TO, baseline; T1, shortly after the start of treatment; T2, 10 weeks after start of treatment; T3, 24 weeks after start of treatment; T4, 48 weeks after start of treatment; TES, targeted selection (T), 


\section{eAppendix 1. Review: Evaluation of Distress Screening on Psychological Well-Being}

\section{Objective}

The objective of this review was to evaluate how screening programs for distress in patients with cancer affect psychological well-being.

\section{Methods}

\section{Search Strategy}

A PubMed search was performed for English-language studies published from inception up to February 20, 2018 using the terms "distress," "screening," "randomized trial," and "cancer OR oncology". Manual searches were performed on relevant systematic reviews. ${ }^{1-3}$

\section{Selection Criteria and Analyses of Eligible Studies}

Eligible articles included English-language studies on patients with any type of cancer at any disease stage and with any treatment that reported original data. Randomized controlled trials (RCTs) were included that compared outcomes of psychosocial well-being between patients who did and did not undergo screening for distress. Studies were excluded if the control group also received screening (even in absence of subsequent discussion or treatment).

\section{Data Collection and Analysis}

We extracted data on design, setting and sample, screening and intervention, and effect on psychological well-being. Results of the trials were evaluated using the narrative synthesis approach.

\section{Results}

A total of 395 studies were retrieved. Of those, 330 studies were excluded after title review, and an additional 54 studies were excluded after abstract review; 11 studies were selected for full-text review, resulting in a total of 6 eligible randomized trials on the effect of screening for distress on psychological well-being. ${ }^{4-9}$ Among the 5 studies that were not included, 4 were excluded because the control group also received (minimal) screening, ${ }^{10-13}$ making it impossible to evaluate the effect of screening itself on psychological well-being, and 1 was excluded because it lacked an outcome measure of well-being. ${ }^{14}$

\section{Screening and Intervention}

eTable 1 provides an overview of the characteristics and outcomes of the included RCTs. Among the 6 studies, 5 screening tools for measuring distress were used: the Distress Thermometer and Problem List, ${ }^{5,6,9}$ the General Health Questionnaire (GHQ-12), ${ }^{7}$ the Screening Inventory of Psychosocial Problems (SIPP),${ }^{4}$ and the Patient Health Questionnaire (PHQ-9) combined with the Generalized Anxiety Screener (GAS). ${ }^{8}$ A distress management plan was used in 4 of the studies ${ }^{5,7-9}$; in 2 studies, no standardized plan was available on how to deal with the screening results.,6

\section{Effect of Screening on Psychological Well-Being}

None of the included studies showed a screening effect on primary well-being outcomes. In one study, however, screening and stepped care resulted in improved referral to psychosocial services. ${ }^{8}$ In Hollingworth et al, ${ }^{6}$ a subgroup analysis suggested that the Distress Thermometer/Problem List might be more effective in patients with better mood states at enrollment. In the trial by Braeken et al, ${ }^{4}$ post hoc analyses revealed a significant association between the intervention with early referral and improved quality of life and anxiety, suggesting that earlier referral might influence short-term quality of life and experienced anxiety in patients.

\section{Conclusions}

In this review, none of the 6 randomized trials evaluating distress screening found an effect on psychological well-being. Despite lack of supporting evidence, several clinical recommendations have been made for screening for psychological distress to be part of standard cancer care. ${ }^{15,16}$ In many of the included RCTs, researchers stated that future studies on screening programs should include distress as a patient outcome; use appropriate samples; include a detailed, theorybased distress management plan; offer staff training; and track staff and patient use of subsequent interventions. 


\section{eAppendix 1. Review: Evaluation of Distress Screening on Psychological Well-Being (cont.)}

\section{References}

1. Meijer A, Roseman M, Delisle VC, et al. Effects of screening for psychological distress on patient outcomes in cancer: a systematic review. J Psychosom Res 2013 75:1-17.

2. Bidstrup PE, Johansen C, Mitchell AJ. Screening for cancer-related distress: summary of evidence from tools to programmes. Acta Oncol 2011;50:194-204.

3. Mitchell AJ. Screening for cancer-related distress: when is implementation successful and when is it unsuccessful? Acta Oncol 2013;52:216-224.

4. Braeken AP, Kempen Gl, Eekers DB, et al. Psychosocial screening effects on health-related outcomes in patients receiving radiotherapy: a cluster randomised controlled trial. Psychooncology 2013;22:2736-2746.

5. Geerse OP, Hoekstra-Weebers JE, Stokroos MH, et al. Structural distress screening and supportive care for patients with lung cancer on systemic therapy: a randomised controlled trial. Eur J Cancer 2017;72:37-45.

6. Hollingworth W, Metcalfe C, Mancero S, et al. Are needs assessments cost effective in reducing distress among patients with cancer? A randomized controlled trial using the Distress Thermometer and Problem List. J Clin Oncol 2013;31:3631-3638.

7. Maunsell E, Brisson J, Deschênes L, Frasure-Smith N. Randomized trial of a psychologic distress screening program after breast cancer: effects on quality of life. J Clin Oncol 1996;14:2747-2755.

8. Singer S, Danker H, Roick J, et al. Effects of stepped psychooncological care on referral to psychosocial services and emotional well-being in cancer patients: a cluster-randomized phase III trial. Psychooncology 2017;26:1675-1683.

9. van der Meulen IC, May AM, Koole R, et al. A Distress Thermometer intervention for patients with head and neck cancer. Oncol Nurs Forum 2018;45:E14-32.

10. Carlson LE, Waller A, Groff SL, et al. Online screening for distress, the 6th vital sign, in newly diagnosed oncology outpatients: randomised controlled trial of computerised vs personalised triage. Br J Cancer 2012;107:617-625.

11. Carlson LE, Groff SL, Maciejewski O, et al. Screening for distress in lung and breast cancer outpatients: a randomized controlled trial. J Clin Oncol 2010;28: 4884-4891.

12. Sarna L. Effectiveness of structured nursing assessment of symptom distress in advanced lung cancer. Oncol Nurs Forum 1998;25:1041-1048.

13. Velikova $G$, Booth $L$, Smith $A B$, et al. Measuring quality of life in routine oncology practice improves communication and patient well-being: a randomized controlled trial. J Clin Oncol 2004;22:714-724.

14. Book K, Dinkel A, Henrich G, et al. The effect of including a 'psychooncological statement' in the discharge summary on patient-physician communication: a randomized controlled trial. Psychooncology 2013;22:2789-2796.

15. Holland JC, Deshields TL, Andersen B, et al. NCCN Clinical Practice Guidelines in Oncology: Distress Management. Version 2.2018. Accessed August 1, 2018. To view the most recent version, visit NCCN.org.

16. Adler NE, Page AE, eds. Cancer Care for the Whole Patient: Meeting Psychosocial Health Needs. Washington, DC: The National Academies Press; 2008. 